\title{
Impacts of village isolation on childhood nutritional status in rural Malawi
}

\author{
Andrew J Claffey ${ }^{1}$ @ , Jennifer C George ${ }^{1}$, Korinne A Thorne ${ }^{1}, K_{\text {Kyle W Zittel }}^{2}$, Jon C Zelasko ${ }^{3}$, David M Holmes ${ }^{4}$ \\ 1 University at Buffalo Jacobs School of Medicine and Biomedical Sciences, Buffalo, New York, USA, ${ }^{2}$ Georgetown University, Department of \\ Orthopedic Surgery; Washington D.C., USA, ${ }^{3}$ George Washington University, Department of Psychiatry; Washington D.C., USA, 4 University at Buffalo \\ Jacobs School of Medicine and Biomedical Sciences, Department of Family Medicine, Buffalo, New York, USA \\ Keywords: healthcare access, road access, stunting, malnutrition, malawi \\ https://doi.org/10.29392/001c.14378
}

\section{Journal of Global Health Reports}

Vol. 4, 2020

\begin{abstract}
Background
According to a recent 2018 survey, the rate of childhood acute malnutrition in Malawi has decreased while the rate of stunting in children under five has remained at $37.4 \%$. Our study assesses the impact of child sex, child age, and household distance from main road access on nutritional status in rural Malawi.
\end{abstract}

\section{Methods}

Anthropometric data was collected on a sample of children aged 0-18 years at three sites in rural Malawi. Z-scores were calculated based on normative height-for-weight and height-for-age World Health Organization (WHO) growth curves. Univariate odds ratios and $95 \%$ confidence intervals (CIs) were calculated for the association of the assessed risk factors with stunting prevalence.

\section{Results}

198 children were assessed [46.4\% male (92)]. Children were grouped ages $0-<2$ years (19, $10 \%), 2-<5$ years $(88,44 \%)$, and $5-\leqslant 18$ years $(91,46 \%) .2 .5 \%$ met criteria for wasting, $8.6 \%$ had moderate stunting, $5.1 \%$ had severe stunting. Data was collected from 3 villages at $<2 \mathrm{~km}(16 \%), 4-5 \mathrm{~km}(35 \%)$ and $>10 \mathrm{~km}(52 \%)$. Village distance of $\geqslant 10 \mathrm{~km}$ from the main $\operatorname{road}(\mathrm{OR}=2.91, \mathrm{CI}=1.26-6.75)$ and child age under 2 years (odds ratio, $\mathrm{OR}=5.54,95 \% \mathrm{CI}$ =1.61-19.1) were both significantly associated with childhood stunting.

\section{Conclusions}

Within our sample, village distance $\geqslant 10 \mathrm{~km}$ from the main road and child age $<2$ years were both significantly associated with stunting. Our results suggest the need for greater resource access and allocation to isolated communities for future public health interventions.

Malawi, a landlocked country in Sub-Saharan Africa, continues to face serious challenges of malnutrition. Malawi is considered one of the five poorest countries in the world, with $71 \%$ of Malawians earning less than the international poverty level of US\$1.90/day. ${ }^{1}$ Malawi's agriculturally-based economy derives nearly $90 \%$ of its revenue, and $80 \%$ of its employment, from exportation of rain-fed maize, tobacco, sugar, and tea. ${ }^{2}$ Furthermore, domestic use of maize or "nsima" is the main source of sustenance for a major portion of the population. Nsima is packed with simple carbohydrates and commonly consumed thrice daily by Malawians of all ages, some as young as one year old. Malawian diets are nutritionally limited and often lead to nutritional deficits in the most vulnerable members of the population. In Sub-Saharan Africa, those most radically affected by malnutrition are children under the age of five. Chronic malnutrition, also known as "stunting," is a condi- tion that often occurs during the first 1000 days of life due to unbalanced nutrient consumption and ultimately leads to irreversible problems with cognitive and physical development. Acute malnutrition, also known as "wasting," is characterized by a lack of adequate caloric intake, contributing to weight loss, edema, and other immediate poor health outcomes. Statistically, only $8 \%$ of Malawian children aged 6-23 months meet the minimum acceptable diet requirements set forth by the World Health Organization (WHO). ${ }^{1} 37.4 \%$ of children under five are considered stunted, compared to an average of $25 \%$ in comparable developing nations. ${ }^{1}$ In addition, $23 \%$ of childhood deaths in Malawi are related to poor nutrition. ${ }^{1}$

Like most resource-deficient countries, Malawi faces challenges with accessing affordable healthcare. A major hurdle in addressing nutritional status of the children in rural villages is the distance from healthcare facilities. In 
Malawi, $84 \%$ of the population lives in rural villages, with only $46 \%$ of Malawians residing within five kilometers $(\mathrm{km})$ of a health facility. ${ }^{3}$ Malawian healthcare is structured in a three-tiered system of primary health clinics, secondary health facilities, and urban central hospitals. The primary health clinics often require over an hour of transit time through a combination of walking, biking, animal-drawn carts, and for those that can afford it, taxi services. ${ }^{4}$ Travel to health clinics often costs nearly one US\$ each direction. ${ }^{4-6}$ Varela et al. concluded that, in Malawi, $56 \%$ of rural populations were able to afford transport to medical clinics. ${ }^{4}$ Costs and travel time are exponentially increased when a higher level of care is needed. Most high acuity hospitals are located in urban centers, and travelling to them from rural areas may cost upwards of nine US\$ for approximately two-and-a-half hours of travel one way. 4

Our study was done in collaboration with Naturally Africa Volunteers (NAV) and the Naturally Africa Foundation. These organizations were developed as a partnership with several Malawian organizations to facilitate support for the needs of those in rural Nkope. NAV's initiatives provide home-healthcare aids, nutritional education, preschool feeding programs, and more to support the community of Nkope. This study strives to identify whether increasing distance from main roads in rural Malawi impacts nutritional deficits that drive chronic stunting in children.

\section{METHODS}

This was a retrospective cohort study using anthropometric data collected by NAV. This data was collected internally by their organization to assess the prevalence of stunting and wasting in children in villages within Mangochi District, Malawi. The data provided by NAV was unidentifiable to our research team, and was collected in compliance with the Malawi Ministry of Health for program development purposes. Due to unidentified participant data, this project was therefore deemed exempt by our home institution from Internal Review Board (IRB) approval. We included children $\leqslant 18$ years of age in three neighboring villages surrounding Nkope, Malawi. Exclusion criteria included those $>18$ yearsof-age, pregnant women, and those whose age could not be identified. Patient variables included age, gender, child height $(\mathrm{cm})$, child weight $(\mathrm{kg})$, village name, and distance ( $\leqslant 2 \mathrm{~km}, 4-5 \mathrm{~km}$, and $\geqslant 10 \mathrm{~km}$ ) from main road access. The main road was defined in this study as a nationally paved interstate that runs through the extent of the country.

Participants were categorized by the village in which they live; the exact locations of participants' homes were not identified but, instead, generalized to the community they belonged to. Village distance from the main road was estimated based on Google mapping due to lack of properly documented distances from road signs or available maps.

The three villages were initially categorized into three groups based on distance in kilometers from the main road: $\leqslant 2 \mathrm{~km}, 4-5 \mathrm{~km}$, and $\geqslant 10 \mathrm{~km}$. No statistical difference was found in the two surrounding villages $\leqslant 5 \mathrm{~km}$ from the main road; therefore, the data from those two villages was combined into one reference group for comparison with the third village. The nutritional status of the third village, which is $\geqslant 10 \mathrm{~km}$ from the main road, was then compared to the reference group ( $\leqslant 5 \mathrm{~km}$ ) based on accessibility to the main road. Children $0-18$ years old living $\leqslant 5 \mathrm{~km}$ or $\geqslant 10 \mathrm{~km}$ from the main road were assigned percentages based on $\mathrm{z}$ scores within the two redefined study groups.

Data was collected by the same three researchers and stored in an offline Microsoft Excel document on a laptop that was brought to each measurement site. Due to most participants being non-English speaking, the same translator was used for the duration of the study when collecting data. Volunteers for the study were recruited biweekly in the morning at three separate wound clinics run by NAV over a three-week period in June 2018. The same weight scale (kg) and tape measure $(\mathrm{cm})$ were utilized for all measurements. Stunting and wasting were defined in accordance with the values established by the WHO height-for-weight and height-for-age curves. For both stunting and wasting, a z-score of >-2 was defined as healthy-mild, a z-score of -2 to -3 was defined as moderate, and a $\mathrm{z}$-score of -3 to -4 was defined as severe.

These data were separated into corresponding z-scores based on height-for-weight and age-for-weight. Univariate odds ratios and $95 \%$ confidence intervals (CI) were then calculated for the association of the assessed risk factors with the prevalence of wasting and stunting.

\section{RESULTS}

198 children from three villages were assessed [46\% male (92)]. Children were grouped ages $0-<2$ years $(19,10 \%), 2-<5$ years $(88,44 \%)$, and 5 - $\leqslant 18$ years $(91,46 \%) .2 .5 \%(5 / 198)$ met criteria for wasting, $8.6 \%(17 / 198)$ had moderate stunting, 5.1\% (10/198) had severe stunting (Table 1). Data was collected from 3 villages at $\leqslant 2 \mathrm{~km}(32 / 198,16 \%), 4-5 \mathrm{~km}$ (71/198, 35\%) and $\geqslant 10 \mathrm{~km}$ (95/198, 52\%). When comparing sample populations between $\leqslant 2 \mathrm{~km}$ and $4-5 \mathrm{~km}$ there were no significant differences noted based on nutritional zscores (Table 1). Village distance of $\geqslant 10 \mathrm{~km}$ from the main $\operatorname{road}(\mathrm{OR}=2.91, \mathrm{CI}=1.26-6.75, \mathrm{P}=.0126)$ (Figure 1$)$ and child age under 2 years $(\mathrm{OR}=5.54,95 \%$ confidence interval, $\mathrm{CI}=1.61-19.1, P=.0067$ ) (Figure 2 ) were both significantly associated with childhood stunting. Data collected showed no significance in wasting (moderate or severe) when assessing for village distance from main road access.

On univariate logistic-regression, no difference was seen in patient gender with regard to stunting or wasting. No significant difference was seen in participants ages 2-18 with respect to stunting or wasting.

On multivariable logistic regression, female sex had no association on stunting $(\mathrm{OR}=0.925,95 \% \mathrm{CI}=.410-2.08)$, nor did age grouping of $2-5$ years $(\mathrm{OR}=2.27,95 \% \mathrm{CI}=$ $.870-5.93)$. Male gender, village distance $>10 \mathrm{~km}$ and age group of 5-18 years of age were used as the reference groups (Table 2).

\section{DISCUSSION}

Utilization of non-governmental organizations (NGOs), mobile health clinics, and community healthcare workers, 
Table 1. Rates of stunting by village

\begin{tabular}{|c|c|c|c|c|}
\hline & $\begin{array}{l}\text { Healthy to mild } \\
\text { range, } \mathrm{n}(\%)\end{array}$ & $\begin{array}{l}\text { Stunting: moderate } \\
\text { range, } \mathrm{n}(\%)\end{array}$ & $\begin{array}{c}\text { Stunting: severe } \\
\text { range, } \mathrm{n}(\%)\end{array}$ & $\begin{array}{c}\text { Total, N } \\
(\%)\end{array}$ \\
\hline $\begin{array}{l}\text { Nkope ( } \leq 2 \mathrm{~km} \text { from the main } \\
\text { road) }\end{array}$ & 41 (91.1) & $3(6.7)$ & $1(2.2)$ & $\begin{array}{c}45 \\
(100)\end{array}$ \\
\hline $\begin{array}{l}\text { Kalumba ( } 4-5 \mathrm{~km} \text { from the } \\
\text { main road) }\end{array}$ & $67(91.8)$ & $4(5.5)$ & $2(2.7)$ & $\begin{array}{c}73 \\
(100)\end{array}$ \\
\hline $\begin{array}{l}\text { Chididi ( } \geq 10 \mathrm{~km} \text { from the } \\
\text { main road) }\end{array}$ & $63(78.75)$ & $10(12.5)$ & $7(8.75)$ & $\begin{array}{c}80 \\
(100)\end{array}$ \\
\hline Total population & $171(86.4)$ & $17(8.6)$ & $10(5)$ & $\begin{array}{c}198 \\
(100)\end{array}$ \\
\hline
\end{tabular}

*A z-score of >-2 was evaluated as healthy to mild, a z-score of -2 to -3 was defined as moderate, and a $\mathrm{z}$-score of -3 to -4 as severe for both stunting and wasting.

Table 2. Multivariate results

\begin{tabular}{|c|c|c|c|c|c|}
\hline & Healthy N (\%) & Stunted N (\%) & OR & $95 \% \mathrm{Cl}$ & $P$-value \\
\hline \multicolumn{6}{|l|}{ Sex } \\
\hline Male & $79(86)$ & $13(14)$ & Ref & Ref & Ref \\
\hline Female & $92(87)$ & $14(13)$ & 0.925 & $(.410-2.08)$ & 0.85 \\
\hline \multicolumn{6}{|l|}{ Village distance } \\
\hline Under 10 km from Main Highway & $108(92)$ & $10(8)$ & Ref & Ref & Ref \\
\hline Over 10 km from Main Highway & $63(79)$ & $17(21)$ & 2.91 & $(1.26-6.75)$ & 0.0126 \\
\hline \multicolumn{6}{|l|}{ Age group } \\
\hline $5-18$ & $84(92)$ & $7(8)$ & Ref & Ref & Ref \\
\hline $2-5$ & $74(84)$ & $14(16)$ & 2.27 & $(.870-5.93)$ & 0.094 \\
\hline $0-2$ & $13(68)$ & $6(32)$ & 5.54 & $(1.61-19.1)$ & 0.0067 \\
\hline
\end{tabular}

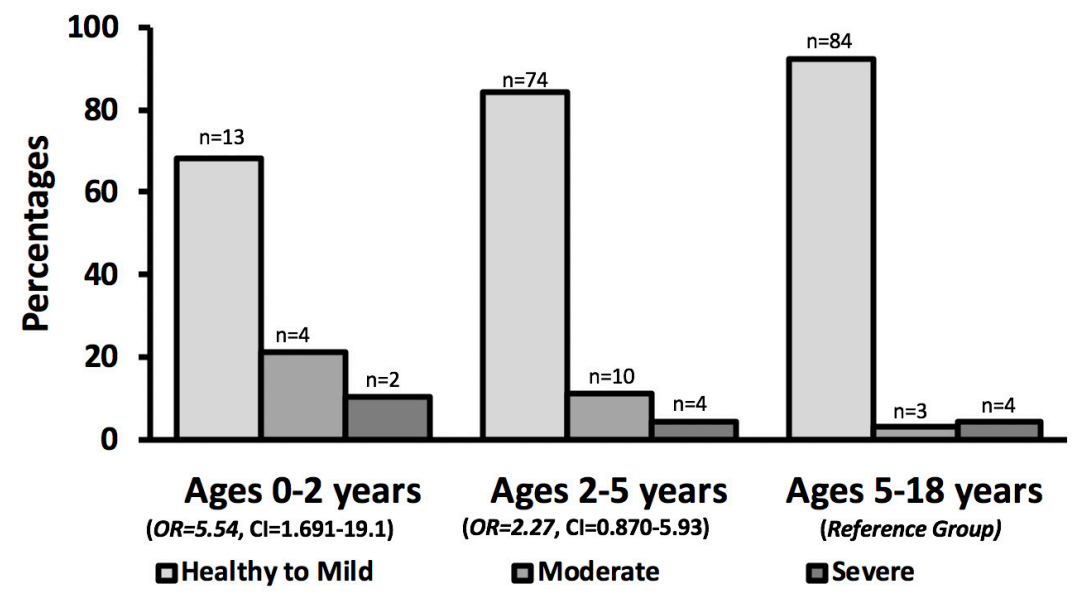

Figure 1. Stunting by age group

*A z-score of >-2 was evaluated as healthy to mild, a z-score of -2 to -3 was defined as moderate, and a $z$-score of -3 to -4 as severe for both stunting and wasting.

are examples of efforts put forth to combat the health, nutritional, and educational needs of communities across Sub-Saharan Africa. Moving these systems from a complementary role to an integral one within the Malawian government health system remains a challenge due to both societal and governmental socio-cultural realities of target implementation sites. ${ }^{7-9}$

The United Nations International Children's Emergency Fund (UNICEF) observes that while severe and moderate malnutrition fell from $32 \%$ in 1990 to $27 \%$ in 2000 in de- 


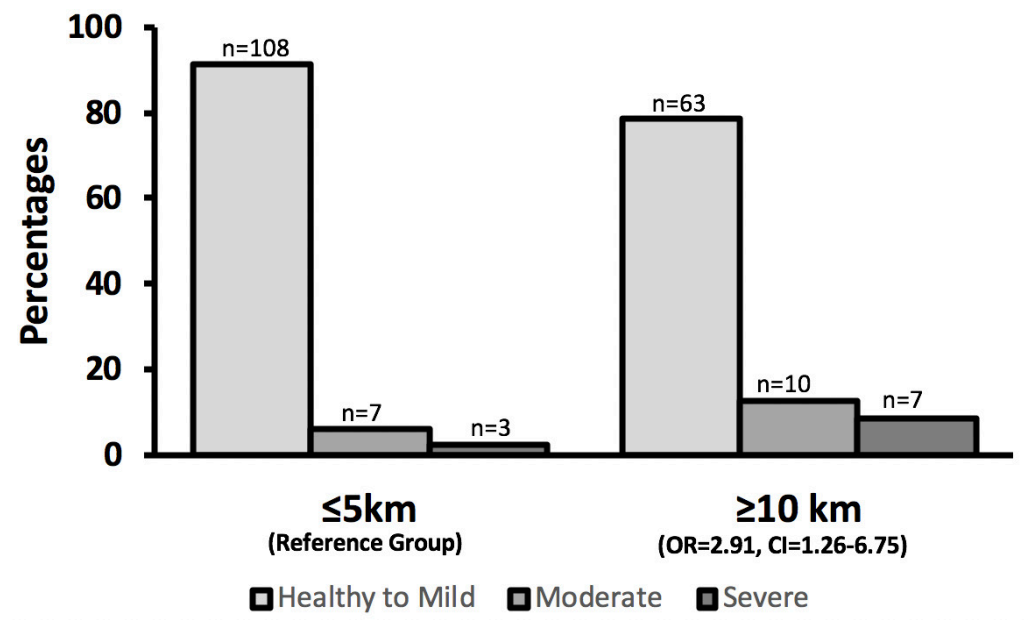

Figure 2. Stunting by village distance

*A z-score of >-2 was evaluated as healthy to mild, a $\mathrm{z}$-score of -2 to -3 was defined as moderate, and a $\mathrm{z}$-score of -3 to -4 as severe for both stunting and wasting

*** Reference Group implies the combination of two comparable villages $\leqslant 5 \mathrm{~km}$ from the main road when compared to children $\geqslant 10 \mathrm{~km}$ from the main road.

veloping countries, the number of malnourished children in Sub-Saharan Africa, continues to rise. ${ }^{7}$ However, according to the 2018 Food and Agriculture Organization of the United Nations statistical database (FAOSTAT), undernourishment in Malawi has remained relatively stagnant at 26\% and 27\% in 2000 and 2016, respectively. ${ }^{1}$ Multiple factors contribute to these observations: namely, healthcare utilization patterns, socio-demographics, underlying illness, and maternal health during pregnancy.

The substantial cost of travel remains one of the greatest barriers to receiving healthcare services. ${ }^{3,6}$ Malawi is equipped with public health services that are delivered free of charge, but unfortunately most of Malawi's rural population resides far from these facilities. Many malnourished children live in lower socioeconomic communities and are less likely to seek medical treatment at distant health centers. Likewise, populations residing in catchment areas of private health facilities have been found to be non-users of health services due to both the inability to afford services and remoteness from public health facilities. ${ }^{6}$

Limited access to healthcare facilities is not the only barrier that poor road infrastructure has on the rural Malawian population. It also has economic impacts that stem from the limited variety of available produce and the elevated costs associated with transporting these goods. Market hurdles diminish community access to nutritional diversity, which may detrimentally impact nutritional status. A review study in 36 countries showed supplementation with multiple micronutrients, as well as protein rich foods, during pregnancy positively impacted childhood nutritional status. ${ }^{10}$ Road access increases access to input and output markets, education systems, health services, and more diversified labor opportunities, which in turn reduces the burden of poverty. ${ }^{11}$ In a study conducted in Cameroon, poverty rates within urban areas from 1996-2007 declined from $41.4 \%$ to $12.2 \%{ }^{11}$ On the contrary, the poverty rate in rural areas only lost four percentage points over that period. The lack of a substantial decrease in poverty in these rural areas was thought to be due to a deficit of road networks in these regions compared to their urban counterparts. ${ }^{10}$ Insuffi- cient access to roads leaves communities economically isolated, decreasing their chances of escaping the poverty cycle. Roads do not just merely improve the standard of living, they themselves represent opportunity. Main roads make it easier to have robust commerce, encourage the use of healthcare services by simplifying travel, and allow for expansion of knowledge through multi-community integration. Generating access to health education and more diverse food sources via road development connects rural communities to these resources with potential to mitigate rates of malnutrition in rural Malawi.

\section{LIMITATIONS}

Our study assessed 198 children from three different villages. Sample size and number of villages studied may limit the ability for the results to be applied to a broader population. Childhood stunting is obviously not an isolated problem; a multitude of confounding factors are inevitable and it is difficult to separate based on village distance from a main road alone. It should also be noted that due to the rural settings in which the data was collected, natural variation did exist in the environment, organization, and layout of the collection sites. The language barrier and inconsistent health records kept by rural clinics and families of participants may also have impacted the precision of documented child age. Child age was recorded in years due to inability to attain an accurate age in months, which may influence the corresponding height-for-weight and height-for-age zscores. The impact of these factors is mitigated by consistency of data collection and statistical analysis.

\section{NEXT STEPS}

Further study is needed to assess distance from main roads and the negative impact this may have on the nutritional status of other rural communities in Malawi and other lowincome countries. In addition, it would be helpful to expand the study by including more children and performing regular follow-up studies to monitor the pattern of changes 
through time. It would be particularly valuable to study nutritional and health status of remote communities before and after roads are built that link the communities to main roads.

As we considered only those communities both $\geqslant 10 \mathrm{~km}$ and $\leqslant 5 \mathrm{~km}$ from the main road, communities living between 5-10 km from the main road were not assessed for nutritional deficits. Also, it should be noted that distant communities had dirt road access that is accessible to vans, bikes, or animal drawn cart. The main difficulty remains that any form of rentable transport departs from the main road, leaving the remaining chore of getting to the main road. Increasing transport from communities to the main road may be a viable solution to diminish health and economic gaps seen in distant villages.

We suggest that governments and aid organizations make it a priority to work with remote communities to build and maintain roads to isolated communities. The roads should be adequate for various types of vehicles to drive on, including motorcycles, bicycles, cars, mid-size busses and mid-size trucks. We also suggest that mobile clinics and malnutrition programs utilize these roads and travel to remote communities on a regular basis to provide healthcare, nutrition assistance and health education. This will likely have a significant impact in preventing and treating stunting and other health problems associated with malnutrition and poor access to healthcare.

The impact of linking communities to main roads cannot be understated, as this allows for communities to advance from sustenance farming models to more diverse trade and commerce. Access to roads, in simple terms, improves the economy and healthcare usage patterns in rural villages; which in turn improves the nutritional status of the future generation. $3,6,11$

\section{CONCLUSIONS}

Within our sample, both village distance $\geqslant 10$ kilometers from a main road and child age less than two years were significantly associated with stunting. This study suggests that malnutrition programs should be expanded to better meet the needs of children less than two years old and those living 10 or more kilometers away from a main road. Programs that are based at clinics or other sites may not be effectively reaching children living in remote villages. Developing road infrastructure to facilitate transportation to clinics, malnutrition programs, markets, work opportunities, etc. may help to improve childhood malnutrition. Addressing these issues will improve access to healthcare, food sources, markets, and jobs which will likely improve the nutrition, health, and economic status of those living in these communities.

Acknowledgements: The authors would like to thank Max Crinnin, BA for editorial assistance, and Marc Crouch, BSc from Naturally Africa Volunteers for aid in study design.

\section{Funding: None}

Authorships contributions: All authors contributed to the design, conduct and writing of the manuscript.

Competing interests: The authors completed the Unified Competing Interest form at www.icmje.org/coi disclosure.pdf (available upon request from the corresponding author), and declare no conflicts of interest.

\section{Correspondence to:}

Andrew J. Claffey, BS

955 Main St, Buffalo

NY 14203; 585-410-2580

ajclaffe@buffalo.edu 


\section{REFERENCES}

1. UNICEF Malawi. Malawi Nutrition Narrative Factsheet 2018. October 2019. https://data.unicef.or $\mathrm{g} /$ resources/levels-and-trends-in-child-malnutritio n-2018. Accessed October 20, 2019.

2. United Nations Children's Fund, World Health Organization, World Bank Group. Levels and trends in child malnutrition: Key findings of the 2018 Edition of the Joint Child Malnutrition Estimates. 2018. htt p://data.unicef.org/nutrition. Accessed October 19, 2019.

3. Geoffroy E, Harries AD, Bissell K, et al. Bringing care to the community: Expanding access to healthcare in rural Malawi through mobile health clinics. Public Health Action. 2014;4(4):252-258. do $\mathrm{i}: 10.5588 /$ pha. 14.0064

4. Varela C, Young S, Mkandawire N, Groen RS, Banza L, Viste A. Transportation Barriers to Access Health Care for Surgical Conditions in Malawi: a cross sectional nationwide household survey. BMC Public Health. 2019;19(1):264. doi:10.1186/s12889-019-657 $\underline{7-8}$

5. Lin BM, White M, Glover A, et al. Barriers to Surgical Care and Health Outcomes: A Prospective Study on the Relation Between Wealth, Sex, and Postoperative Complications in the Republic of Congo. World J Surg. 2017;41(1):14-23. doi:10.1007/s 00268-016-3676-x
6. Munthali AC, Mannan H, MacLachlan M, Swartz L, Makupe CM, Chilimampunga C. Non-use of Formal Health Services in Malawi: Perceptions from Nonusers. Malawi Medical Journal. 2014;26(4):126-132.

7. Engelbert-Bain L, Awah PK, Geraldine N, Kindong NP, Sigal Y, Bernard N, et al. Malnutrition in SubSaharan Africa: Burden, causes and prospects. Pan African Medical Journal. 2013;15:120-129.

8. Sadruddin S, Pagnoni F, Baugh G. Lessons from the integrated community case management (iCCM) Rapid Access Expansion Program. Journal of Global Health. 2019;9(2):1-3. doi:10.7189/jogh.09.020101

9. Miller NP, Richards AK, Marx MA, Checchi F, Kozuki N. Assessing Community Health worker service Delivery in Humanitarian Settings. Journal of Global Health. 2020;10(1):1-4. doi:10.7189/jogh.10.01 $\underline{0307}$

10. Bhutta ZA, Ahmed T, Black RE, et al. What works? Interventions for maternal and child undernutrition and survival. The Lancet. 2008;371(9610):417-440. do $\mathrm{i}: 10.1016 / \mathrm{s} 0140-6736(07) 61693-6$

11. Gachassin M, Najman B, Raballand G. Impact of Roads on Poverty Reduction: A Case Study of Cameroon. The World Bank Africa Region Transport Unit; 2010. 